is as set). If there is a gap in the middle of the band, the diameter of the bar is less than the scale reading, while a bright central zone caused by the images overlapping indicates that the diameter is greater. First experiments show that deviations in diameter of about 0.005 in. can be detected.

Leaving the theme of automation, an interesting sidelight on the technique of research was provided by the Ironmaking Division. Although the blast furnace is a remarkably efficient vessel for the largescale exercise in physical chemistry which ironmaking represents, there is still much to be learned about the course of the reduction process. There are severe limits on what can be deduced from experimental work on a blast furnace, and the Division therefore developed laboratory apparatus to simulate the reactions taking place in the blast furnace. The Scice apparatus (stationary charge in controlled environment) metaphorically turns the blast furnace 'inside-out'. In the blast furnace the charge moves down the stack, encountering changing conditions and undergoing various reactions; in Scice the charge is held stationary while gas of varying compositions and temperatures corresponding to these changing conditions is passed through it and reacts with it. By controlling the conditions continuously, the ironmaking process can be reproduced and its reactions studied with relative ease.

The practicability of this approach was originally proved in the laboratory by experiments using a charge container of three inches diameter. A much larger and more elaborate version has now been installed at the Battersea Laboratories. It incorporates a gas producer, gas absorbers, gas booster, electric heater for the gas, a reaction chamber 20 in. in diameter by 24 in. high, dust cyclone, and a gas cooler. Instrumentation has been provided for flow-rates, temperatures, pressures and gas compositions, with provision for easy control of the variables. This scaled-up version of the original bench conception provides a unique tool with which to solve some of the remaining unknowns about blast furnace operation.

Also housed at Battersea is the Association's Operational Research Department, which now consists of three Sections: Computer Applications, Operational Investigations and Human Factors.

The first of these is primarily concerned with helping the steel industry to make use of the electronic computer. This involves the use of the computer not only as a research tool but also as an administrative and/or production aid. Using the Ferranti Pegasus computer installed at Battersea in 1958, the Section has carried out extensive studies of the feasibility and economics of using computers for such familiar problems as production scheduling, stock control, wage calculation, plant and process control, and allocation of materials, and already much valuable data have been collected.

The Operational Investigations Section is operating a service - at present confined to the Association's member firms-whereby the Department's $\theta \mathrm{X}$ perience and facilities can be used to supplement managerial experience with forecasts of the effects of alternative policies. A typical problem, involving a decision on stock control methods, was illustrated by displays. The example taken was a company keeping large stocks of billets to ensure against production hold-ups. This involved problems of lockedup capital and periodic rises in storage and transport costs.

The first step was to analyse existing order and stock control methods. From this, and from quantita. tive records, the main characteristics of production and raw material delivery over a long period were mapped out, and the effects of different control methods simulated on paper and carefully studied.

Eventually, a set of 'ordering rules' was drawn up which in practice proved so successful as to release $£ 100,000$ of working capital by reducing the average stock-level, and a further saving of $\operatorname{some} £ 6,000$ annually by reduced labour and transport costs.

The Human Factors Section of the Department is concerned with such things as accident prevention, protection against heat and injury, and the broad subject of ergonomics, or 'fitting the machine to the man'. In this latter field, displays showed many advances in control equipment design, aimed at reducing operator fatigue, eliminating strain and increasing efficiency. An experimental control point was on display incorporating variable hand (and foot) controls, which has proved the genesis of a series of improvements already being adopted in production practice.

It is, of course, impossible to give other than an arbitrary selection of the features of the display which, in any event, was representative of a part only (about one-third) of the whole programme of the British Iron and Steel Research Association. This account, however, provides an indication of some types of problem being tackled and of the methods of approach.

D. U. HuNT

\title{
COMPUTER LABORATORY AT THE UNIVERSITY OF LIVERPOOL
}

$\mathrm{T}$ HE University of Liverpool has had a Mathematical Laboratory for more than twenty-five years - it was established by Prof. L. Rosenhead in 1934 shortly after he became head of the Department of Applied Mathematics. The primary object of the Laboratory was always to train students in the honours school of mathematics and research students in other schools in the basic methods of numerical analysis applied to all branches of science.

The Laboratory has always been well equipped with accounting machines as well as desk calculating machines. An important feature of the teaching in the Laboratory has been the insistence on the fullest possible exploitation of all types of calculating aids, and much effort has been spent on not only investigating the possible uses of machines but also on developing methods suitable for them.

The spectacular post-war growth in the domands for numerical analysis has led to very greatly inereased demands being made on the Laboratory; the problems received for solution have been growing more numerous, more complex and greater in scope. At first, the noed was met in part by making use of punched card accounting machinery, and later by 
using the facilities of electronic computing establishments elsewhere-particularly at the University of Manchester, the generosity of which in this respect has been greatly appreciated by several other northern universities as well as Liverpool. More than four years ago, however, it was already clear that the University of Liverpool should be equipped with its own computer, and detailed plans were made for the expansion of the Laboratory. It was therefore with very keen disappointment that the University learned two years ago that money could not be provided at that time by the University Grants Committee for the provision of a computer.

A survey made in the University had established the faet that the lack of an adequate computing service was causing research in some departments to be retarded seriously - particularly in the fields of nuclear physics and oceanography. In view of this situation, the University Council decided that a computer must somehow be provided and an appeal was launched among local business concerns and friends of the University for donations towards the cost of purchasing a machine. The response was generous particularly as the appeal was made within a year of the major appeal to finance the general building development of the University-and as a result the University was able to place an order with the English Electric Co., Ltd., for a Deuce, the remaining balance of the cost being advanced by the University itself. At the same time the staff of the Laboratory was increased and its name changed to the Computer Laboratory, Mr. Andrew Young being appointed as its first director.

The machine was installed and came into operation last July. It is a 64-column Deuce, which is at present equipped with punched card input and output mech. anisms. A comprehensive range of punched card ancillary equipment--card punches, sorter, reproducer and tabulator- has also been installed; a cardoperated typewriter is due for early delivery. In addition, paper tape input and output devices and the necessary tape editing ancillary equipment have been ordered, but have not yet been delivered.
The Computer Laboratory was officially inaugurated at an open day held on October 28, when the University entertained donors to the appeal fund and members of Council and Senate. The guests were welcomed by the Vice-Chancellor, Sir James Mountford, and were shown over the Laboratory by the staff; the Director gave an account of the work being done in the Laboratory.

It is already clear that the computer is meeting a very real need. Extensive use of the machine is being made, as expected, by the Departments of Applied Mathematics, Physics-mainly analysing results of experiments made on the University's large synchrocyclotron-and Oceanography as well as several departments in the Faculty of Engineering, including the new Department of Building Science.

What has surprised - and gratified-the University, however, is the unexpectedly large use of the machine by departments which had not hitherto been expected to use it extensively, if at all. Sorne of the most frequent users are members of a group of physiologists working on a problem of liver function. Members of the Department of Psychology and of the Medical Research Council are now analysing the results of gerontological studies with the computer, which, because of its ability to cope with the heavy arithmetic involved in factor analysis, has enabled them to extend their work. In addition, educational, economic and social scientific surveys have been helped by the new computing facilities available.

Training in programming and using the computer and its ancillary equipment is given regularly to members of the staff of the University, research students, and to outside users, a number of whom are making use of the machine on a basis of time-hire.

It is now a commonplace occurrence that the installation of a computer leads to an expansion in the scope of the work undertaken in an institution, and it is already abundantly clear that in this respect the installation in Liverpool will prove to be no exception. The University is proud of its new project, and is confident that the decision to embark on it will be fully justified.

\section{BRITISH ELECTRICAL AND ALLIED INDUSTRIES RESEARCH ASSOCIATION}

\begin{abstract}
A NEW format has been adopted for the 1958 annual report of the Electrical Research Association (Thirty-eighth Annual Report for the year ended 31st December 1958. Pp. 103. Leatherhead: Electrical Research Association, 1959). The report, which is attractively reproduced, departs from previous practice in having some fifteen illustrations, mostly photographs relating to researeh projects. One diagrammatic illustration of special interest shows the proportions of the income of the Association coming from various sources and the distribution of expenditure among the main fields of research, in administration and in services to members.

The total income of the Association for the year was just over $£ 458,000$, subscriptions from members totalling some $£ 213,000$, income from directly sponsored researches earning nearly $£ 113,000$, and the grant from the Department of Scientific and
\end{abstract}

Industrial Research contributing $£ 100,000$. From the chart showing the distribution of expenditure it appears that some 9 per cent is used in administration. A slightly greater amount represents services to members which, in addition to general technical liaison, cover the answering of requests for advice and information and the provision of abstracts. Research expenditure appears under seven headings, divided as percentages of the total exponditure, roughly, as follows :

$\begin{array}{cccc}\text { Properties of materials } & 19 & \text { Applications of electricity } & 12 \\ \text { System problems } & 14 & \text { Transmission } & 6 \\ \text { Control and transformation } & 10 & \text { Specialized plant } & 10 \\ \text { Miscellaneous researches } 9 & \end{array}$

On the basis of expenditure, properties of materials thus represents, by a substantial margin, the biggest research effort of the Association, and it is evident from the report that this effort, which is devoted largely to insulation, has contributed both to funda- 